\title{
Microwave-assisted determination of total mercury and methylmercury in sediment and porewater
}

\author{
S. Niessen ${ }^{*}$, N. Mikac ${ }^{2}$ and J.-C. Fischer ${ }^{1}$ \\ ${ }^{1}$ Laboratory for Analytical and Marine Chemistry, UPRES A 8013, CNRS, University of Lille, Bât. C8, \\ 59655 Villeneuve d'Ascq Cedex, France \\ ${ }^{2}$ Centre for Marine and Environmental Research Zagreb, Rudjer Boskovic Institute, \\ P.O. Box 1016, 10000 Zagreb, Croatia
}

\begin{abstract}
Existing methods for total mercury and methylmercury determination in sediment and porewaters were improved by applying open microwave heating for extraction of $\mathrm{Hg}$ species from the sample and decomposition of $\mathrm{MeHg}$ prior to detection as $\mathrm{Hg}$ (II) by CV AFS. It was shown that nitric acid can quantitatively leach $\mathrm{Hg}$ from sediment, already at a low microwave power ( $30 \mathrm{~W}, 5 \mathrm{~min}$ ). Methylmercury can be quantitatively leached from sediment by dilute sulphuric acid (1 mol/L) at a power of $60 \mathrm{~W}$ during 5 minutes, without being decomposed. So obtained extract can be further distilled with a reduced possibility for artefactual $\mathrm{MeHg}$ formation, as it contains much lower levels of inorganic $\mathrm{Hg}$, compared to the original sediment. Microwave-assisted $\mathrm{BrCl}$ oxidation was shown to be more effective for decomposition of $\mathrm{MeHg}$ and stable organomercury complexes in water solutions (sediment distillate and porewater), as compared with $\mathrm{BrCl}$ oxidation at room-temperature. Therefore, the application of low-power microwave digestion can significantly improve determination of $\mathrm{Hg}$ species in sediment and porewater, both in terms of time and efficiency.
\end{abstract}

Keywords. Mercury - methylmercury - sediment - microwave digestion.

\section{Introduction}

Microwave-assisted extraction methods for sample preparation have been evaluated in various environmental applications, as are total digestion for element analysis or extraction of selected organic compounds. This technique has been confirmed as a method of choice over conventional procedures for digestion of mineral and biological samples for total $\mathrm{Hg}$ determination [1,2,3], due to a shorter extraction time, a higher extraction efficiency and easier control of digestion parameters. Both closed and open microwave systems are used for the digestion of samples for the total $\mathrm{Hg}$ analyses. However, determination of the total $\mathrm{Hg}$ in environmental samples is not sufficient, as $\mathrm{Hg}$ is partly in the form of methylmercury ( $\mathrm{MeHg}$ ), which is considerably more toxic than the inorganic $\mathrm{Hg}$. A particularly difficult task is the determination of $\mathrm{MeHg}$ in sediment, where it makes a very low percentage of the total $\mathrm{Hg}(<2 \%)$. Only recently, an open low-power focused microwave system has been verified as an appropriate tool for preparation of solid samples for organometallic speciation analysis [4]. It has been used for developing of the isolation procedure of $\mathrm{MeHg}$ in sediment based on the microwave-assisted leaching of $\mathrm{MeHg}$ with dilute acids [5].

In this work, the application of open microwave system for the total $\mathrm{Hg}$ and $\mathrm{MeHg}$ determination in sediment and porewater is described. Microwave-assisted leaching of the total $\mathrm{Hg}$ and $\mathrm{MeHg}$ from sediment with an acid extractant, provided a rapid way of separation of these species from the matrix prior to detection by CV AFS (cold vapour atomic fluorescence spectroscopy). Microwave-assisted $\mathrm{BrCl}$ oxidation was proved to be more effective for the decomposition of $\mathrm{MeHg}$ and stable organomercury complexes in solution (distillate or porewater), as compared with $\mathrm{BrCl}$ oxidation at room temperature.

\section{Material and methods}

\section{Reagents}

Acids used were of analytical quality $\left(\mathrm{HNO}_{3}, \mathrm{HCl}\right)$ or suprapur grade $(\mathrm{HCl}$, Merck). $\mathrm{Hg}$ standard was prepared from stock standard solution $(1 \mathrm{~g} / \mathrm{L}$, Merck). A standard solution was prepared weekly in $10 \% \mathrm{HNO}_{3}$ and $0.01 \%$ of $\mathrm{K}_{2} \mathrm{Cr}_{2} \mathrm{O}_{7}$, whereas reference standard solutions were prepared daily in $1 \% \mathrm{HNO}_{3}$. A reductant solution $\left(5 \% \mathrm{SnCl}_{2}\right.$ in $\left.10 \% \mathrm{HCl}\right)$ was prepared by dissolving $\mathrm{SnCl}_{2}$ in concentrated $\mathrm{HCl}$ and diluting with water. The certified reference sediments used for verification were PACS-1 (National Research Council of Canada - NRCC) and CRM 580 (Community Bureau of Reference of the European Communities - BCR).

\footnotetext{
* Correspondence and reprints

Received July 20, 1999, revised October 29, 1999, accepted November 5, 1999.
} 


\section{Original articles}

\section{Instruments}

Sample digestion was carried out in a single-mode reflux focused microwave system (Microdigest A-300, Prolabo, Paris, France) with a maximum power setting of $300 \mathrm{~W}$. Specially designed glass vessels and the construction of the system allow digestion under atmospheric pressure without any microwave leakage. For $\mathrm{Hg}$ detection a CV AFS method was used, consisting of vapour generator (PSA 10.003), a gold platinum trap (PSA 10.501 Galahad) connected with an atomic fluorescence detector (PSA 10.023 Merlin) and is described in details elsewhere $[6,7]$.

\section{Procedures}

For the total $\mathrm{Hg}$ determination wet or dry sediment (0.05$0.1 \mathrm{~g}$ ) was digested with $5 \mathrm{~mL}$ of concentrated $\mathrm{HNO}_{3}$ in a glass vessel for microwave digestion at a chosen power setting (10-20\%) for 3-5 min. The sample was left to cool, transferred into Teflon tube and centrifuged for $10 \mathrm{~min}$ at $10000 \mathrm{rpm}$. The supernatant was diluted according to the concentration range of the samples for $\mathrm{Hg}$ detection by $\mathrm{CV}$ AFS. The sediment porewater was isolated from the sediment under the nitrogen atmosphere by centrifugation and acidified with $1 \% \mathrm{HNO}_{3}$. Reactive $\mathrm{Hg}$ was determined within few days of sampling after $\mathrm{SnCl}_{2}$ reduction. The total $\mathrm{Hg}$ in porewater was measured after $\mathrm{Hg}$ oxidation by $\mathrm{BrCl}$, overnight at room temperature [8], or within $3 \mathrm{~min}$ at a power of $30 \mathrm{~W}$ in the microwave oven. For comparison samples were also decomposed by UV irradiation (150 W UV lamp) within 12 hours [9]. MeHg was isolated from the sediment matrix by distillation of the entire sediment or the sediment leachate. For the sediment distillation $8.5 \mathrm{~mL}$ of water, $1 \mathrm{~mL}$ of $10 \% \mathrm{NaCl}$ and $1 \mathrm{~mL}$ of $8 \mathrm{~mol} / \mathrm{L} \mathrm{H}_{2} \mathrm{SO}_{4}$ [10] was added to $0.2-0.5 \mathrm{~g}$ of dry or wet sample. To obtain the sediment leachate dry sample $(0.2-0.5 \mathrm{~g})$ was digested with $10 \mathrm{~mL}$ of $1 \mathrm{~mol} / \mathrm{L} \mathrm{H}_{2} \mathrm{SO}_{4}$ in the glass vessel for microwave digestion at a power setting of $20 \%(60 \mathrm{~W})$ for $5 \mathrm{~min}$. After cooling the sample solution was centrifuged for $10 \mathrm{~min}$ at $10000 \mathrm{rpm}$. An aliquot of supernatant $(8 \mathrm{~mL})$ was transferred into distillation vessel, $1 \mathrm{~mL}$ of $10 \% \mathrm{NaCl}$ was added and volume was adjusted to $10 \mathrm{~mL}$ with $1 \mathrm{~mol} / \mathrm{L} \mathrm{H}_{2} \mathrm{SO}_{4}$. Distillation was performed in all-glass system at a temperature of $160{ }^{\circ} \mathrm{C}$ under a nitrogen flow-rate of $60 \mathrm{~mL} / \mathrm{min}$. The distillate $(8-8.5 \mathrm{~mL})$ was diluted to $20 \mathrm{~mL}$ with $\mathrm{Hg}$-free water and an aliquot was checked for any inorganic $\mathrm{Hg}$ present. In the rest of the sample $\mathrm{MeHg}$ was decomposed by $\mathrm{BrCl}$ oxidation $(0.25 \mathrm{~mL}$ of $\mathrm{BrCl}$ was added to $10 \mathrm{~mL}$ of sample and left overnight), or by microwave-assisted $\mathrm{BrCl}$ oxidation $(0.05 \mathrm{~mL}$ of $\mathrm{BrCl}$ was added to $10 \mathrm{~mL}$ of sample and digested for 3 minutes at a power of $30 \mathrm{~W}$ ) and detected by $\mathrm{CV}$ AFS as inorganic $\mathrm{Hg}$.

\section{Results and discussion}

Applied microwave irradiation must be strong enough to achieve a quantitative $\mathrm{Hg}$ extraction from sediment, but in the same time sufficiently mild to avoid $\mathrm{Hg}$ losses by overheating and/or volatilisation. Experiments performed on the certified reference sediment PACS-1 (Tab. I) showed that digestion with concentrated $\mathrm{HNO}_{3}$ for 3 min at $60 \mathrm{~W}(20 \%)$ was insufficient for a quantitative $\mathrm{Hg}$ extraction from PACS1 , while digestion for $5 \mathrm{~min}$ at $90 \mathrm{~W}$ or $10 \mathrm{~min}$ at $60 \mathrm{~W}$ caused losses of $\mathrm{Hg}$ as a consequence of sample overheating. Microwave irradiation during $5 \mathrm{~min}$ at $30 \mathrm{~W}(10 \%)$ was found to offer optimum conditions for leaching of the total $\mathrm{Hg}$ from PACS-1 with $\mathrm{HNO}_{3}$. A mixture of different acids $\left(\mathrm{HNO}_{3}, \mathrm{HCl}, \mathrm{H}_{2} \mathrm{SO}_{4}\right)$ is usually used for the total $\mathrm{Hg}$ extraction from mineral samples $[1,2]$. The results obtained demonstrate that, by applying an adequate microwave procedure, $\mathrm{HNO}_{3}$ only is sufficient for a quantitative leaching of $\mathrm{Hg}$, thus providing a very simple and rapid manner for $\mathrm{Hg}$ determination in sediments.

It has been recently demonstrated that distillation, one of the frequently used methods for $\mathrm{MeHg}$ isolation from solid matrices [10], was prone to artefact formation of $\mathrm{MeHg}$ during distillation (up to $0.1 \%$ of the total $\mathrm{Hg}$; $[11,12]$ ). The artefact may be significant in sediments where naturally occurring $\mathrm{MeHg}$ usually makes less than $2 \%$ of the total $\mathrm{Hg}$. In addition, clogging of the system due to formation of the precipitate during distillation can create difficulties during distillation of some types of sediments. Both disadvantages could be minimised by extracting $\mathrm{MeHg}$ from sediment particles before distillation and carrying out a distillation of the sediment leachate. This objective could be achieved by the microwave-assisted leaching of $\mathrm{MeHg}$ from sediment with dilute mineral acids [5]. As it was shown that the optimum conditions for $\mathrm{MeHg}$ distillation were obtained using dilute $\mathrm{H}_{2} \mathrm{SO}_{4}$ [13], a leaching of $\mathrm{MeHg}$ from sediments with dilute $\mathrm{H}_{2} \mathrm{SO}_{4}$ was investigated. A study on the stability of $\mathrm{MeHg}$ in $1 \mathrm{~mol} / \mathrm{L} \mathrm{H}_{2} \mathrm{SO}_{4}$ (Tab. II) showed that

Table I. Optimisation of microwave digestion of sediments with concentrated $\mathrm{HNO}_{3}$ for the total $\mathrm{Hg}$ analysis in PACS-1.

\begin{tabular}{lcc}
\hline Power $(W)$ & Time $(\mathrm{min})$ & $H g(\mathrm{mg} / \mathrm{kg} \mathrm{d.w.})$ \\
\hline 30 & 5 & $4.63 \pm 0.12$ \\
60 & 3 & $4.13 \pm 0.06$ \\
60 & 5 & $4.46 \pm 0.12$ \\
60 & 10 & $3.80 \pm 0.17$ \\
90 & 5 & $3.56 \pm 0.12$ \\
\hline
\end{tabular}

- certified value for $\mathrm{Hg}$ in PACS-1: $4.57 \pm 0.16 \mathrm{mg} / \mathrm{kg}$

Table II. Influence of microwave parameters on the stability of $\mathrm{MeHg}$ in $1 \mathrm{~mol} / \mathrm{L} \mathrm{H}_{2} \mathrm{SO}_{4}$.

\begin{tabular}{lccc}
\hline $\begin{array}{l}\text { Power } \\
(W)\end{array}$ & $\begin{array}{c}\text { Time } \\
(\text { min })\end{array}$ & $\begin{array}{c}\text { MeHg added } \\
(\text { ng/L) }\end{array}$ & $\begin{array}{c}H g(I I) \\
\text { found }(n g / L)^{*}\end{array}$ \\
\hline 30 & 5 & $20-40$ & $<2$ \\
60 & 5 & $20-40$ & $<2$ \\
90 & 5 & $20-40$ & $2-5$ \\
\hline
\end{tabular}

* a presence of $\mathrm{Hg}$ (II) in solution indicates $\mathrm{MeHg}$ decomposition during microwave irradiation ( $2 \mathrm{ng} / \mathrm{L}$ is detection limit of the method) 
during irradiation for $5 \mathrm{~min}$ and power up to $60 \mathrm{~W} \mathrm{MeHg}$ was not decomposed. The experiment on the leaching of sediment with $1 \mathrm{~mol} / \mathrm{L} \mathrm{H}_{2} \mathrm{SO}_{4}$ demonstrated that only a minimum amount of inorganic $\mathrm{Hg}$ (regularly less than $1 \%$ of $\left.\mathrm{Hg}_{\text {tot }}\right)$ was extracted from sediment under such conditions. It is important from the point of view of possible artefactual $\mathrm{MeHg}$ formation, as a very low amount of $\mathrm{Hg}$ in the solution which is subjected to distillation, will allow less formation of $\mathrm{MeHg}$ during distillation. If up to $0.1 \%$ of the inorganic $\mathrm{Hg}$ could be methylated [11,12] it would represent maximum $0.001 \%$ of the total $\mathrm{Hg}$ originally present in sediment. This amount will be minor compared with a percentage of $\mathrm{MeHg}$ naturally occurring in sediments (0.1-2\%). A comparison of $\mathrm{MeHg}$ determination by distillation of the entire sediment and $\mathrm{H}_{2} \mathrm{SO}_{4}$ extract was performed on the certified reference sediment CRM 580 and on the several sediments taken from the Seine estuary (Tab. III). A good agreement between different isolation methods indicated that under the microwave condition used, $1 \mathrm{~mol} / \mathrm{L} \mathrm{H}_{2} \mathrm{SO}_{4}$ extracted quantitatively $\mathrm{MeHg}$ from both CRM 580 and this type of natural sediments $\left(\mathrm{Hg}_{\text {tot }}: 200-700 \mathrm{ng} / \mathrm{g}\right.$, orgC: 2-5\%). Tseng et al. [5] obtained, using microwave leaching $\left(60 \mathrm{~W}, 3 \mathrm{~min}\right.$ ) with $1 \mathrm{~mol} / \mathrm{L} \mathrm{H}_{2} \mathrm{SO}_{4}$, too low $\mathrm{MeHg}$ recovery from certified sediment samples. A longer irradiation time and thus more powerful extraction, could probably explain the greater efficiency of $\mathrm{MeHg}$ extraction from sediments obtained with our procedure. Similar $\mathrm{MeHg}$ concentrations obtained by distillation of the whole sediment and $\mathrm{H}_{2} \mathrm{SO}_{4}$ extract suggest that artefact formation of $\mathrm{MeHg}$ during distillation of the whole sediment is not significant, compared to the natural $\mathrm{MeHg}$ level in these samples. For CRM 580 it is in accordance with the results showing that distillation based techniques are in good agreement with techniques not involving distillation $[14,15]$.

In the method used in this work $\mathrm{MeHg}$ in the sediment distillate is finally detected as inorganic mercury. Therefore, it should be completely transformed to $\mathrm{Hg}$ (II) before $\mathrm{CV}$ AFS detection. For such purpose a decomposition by UV light or a chemical oxidation by $\mathrm{BrCl}$ can be used. For a quantitative oxidation of $\mathrm{MeHg}$ by $\mathrm{BrCl}$ at room temperature, a rather high concentration of $\mathrm{BrCl}(2.5 \%)$ during prolonged time (several hours) was required. It was suggested that digestion of $\mathrm{MeHg}$ by $\mathrm{BrCl}$ could be promoted at elevated temperature [16], or by microwave-assisted $\mathrm{BrCl}$ oxidation used in the on-line method for $\mathrm{Hg}$ determination in slurried samples [17]. Our results (Tab. IV) showed that microwave-assisted $\mathrm{MeHg}$ oxidation by $\mathrm{BrCl}$ was very efficient and that $\mathrm{Hg}$ demethylation can be accomplished within few minutes by using much lower $(0.5 \%) \mathrm{BrCl}$ concentration. Three different methods of $\mathrm{MeHg}$ decomposition in distillate $(\mathrm{BrCl}, \mathrm{UV}, \mathrm{BrCl}+\mathrm{MW})$ tested on several sediment samples gave comparable results for $\mathrm{MeHg}$ level in different types of sediment (Tab. III).

Procedure for the total $\mathrm{Hg}$ determination in sediment porewaters usually include oxidation of the non-labile $\mathrm{Hg}$ fraction with $0.5 \% \mathrm{BrCl}$ prior to $\mathrm{Hg}(\mathrm{II})$ reduction with $\mathrm{SnCl}_{2}$. Analysis of porewaters isolated from the sediment of

Table III. Comparison of MeHg determination by different isolation and decomposition methods in CRM 580 and in sediments from the Seine estuary.

\begin{tabular}{lcccc}
\hline Sediment sample & Method A & $\begin{array}{c}\text { MeHg concentration }(\mu \mathrm{g} / \mathrm{kg} \mathrm{d.w.}) \\
\text { Method B }\end{array}$ & Method C MeHg of HgT in sediment \\
\hline CRM 580 & $72.6 \pm 6.2$ & - & $73.8 \pm 5.8$ & 0.06 \\
Coastal sediment 1 & $0.7 \pm 0.1$ & 0.9 & $0.8 \pm 0.1$ & 0.20 \\
Coastal sediment 2 & $1.9 \pm 0.2$ & 2.0 & $1.8 \pm 0.2$ & 0.40 \\
Estuarine sediment 1 & $3.3 \pm 0.3$ & 2.9 & $3.3 \pm 0.4$ & 1.24 \\
Estuarine sediment 2 & $5.3 \pm 0.4$ & 5.0 & $5.7 \pm 0.5$ & 1.72 \\
Estuarine sediment 3 & $0.1 \pm 0.1$ & 0.1 & $0.2 \pm 0.1$ & 0.05 \\
Riverine sediment & $1.4 \pm 0.2$ & 1.3 & $1.1 \pm 0.2$ & 0.82 \\
\hline
\end{tabular}

A - distillation of sediment with a final $\mathrm{MeHg}$ decomposition by $\mathrm{BrCl}$

$\mathrm{B}$ - distillation of sediment with a final $\mathrm{MeHg}$ decomposition by UV

$\mathrm{C}$ - distillation of $\mathrm{H}_{2} \mathrm{SO}_{4}$ extract with a final $\mathrm{MeHg}$ decomposition by $\mathrm{BrCl}$ or $\mathrm{BrCl}+\mathrm{MW}$

- certified value for MeHg in CRM 580: $75.5 \pm 5.0 \mu \mathrm{g} / \mathrm{kg}$

- detection limit of the method is $0.1 \mu \mathrm{g} / \mathrm{kg}$

Table IV. Influence of microwave parameters on the oxidation of $\mathrm{MeHg}$ by $\mathrm{BrCl}$ solution in $\mathrm{MQ}$ water.

\begin{tabular}{lcccc}
\hline BrCl added $(m L / m L$ or $\%)$ & Power $(W)$ & Time $($ min $)$ & MeHg added $(n g / L)$ & MeHg found (\%) as Hg(II) \\
\hline $0.5 / 20$ or $2.5 \%$ & 30 & 5 & $10-30$ & $98-105$ \\
$0.25 / 20$ or $1.25 \%$ & 30 & 5 & $10-30$ & $95-100$ \\
$0.1 / 20$ or $0.5 \%$ & 30 & 5 & $10-30$ & $95-105$ \\
$0.05 / 10$ or $0.5 \%$ & 30 & 3 & $20-40$ & $95-108$ \\
\hline
\end{tabular}




\section{Original articles}

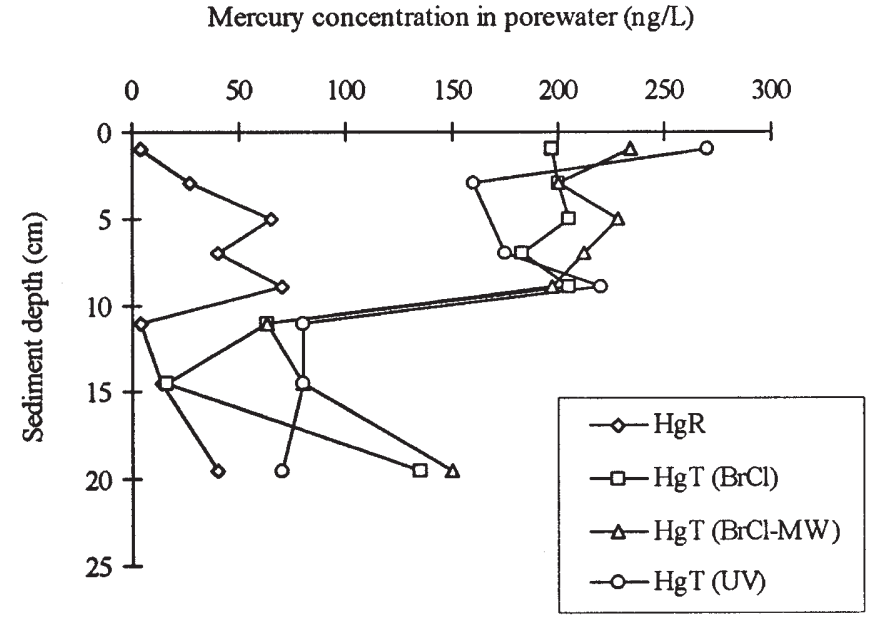

Fig. 1. Porewater mercury profile in sediment core of the Seine estuary sampled in September 1996 (HgR - reactive mercury, HgT - total mercury).

the Seine estuary demonstrated that oxidation with $\mathrm{BrCl}$ is not always sufficient. While in sediment collected in September 1996 the comparable total $\mathrm{Hg}$ levels in porewater were found after $\mathrm{UV}, \mathrm{BrCl}$ and microwave-assisted $\mathrm{BrCl}$ oxidation (Fig. 1), in samples collected in March 1997 significantly lower concentrations were obtained after $\mathrm{BrCl}$ oxidation only (Fig. 2), indicating an incomplete $\mathrm{Hg}$ oxidation by $\mathrm{BrCl}$ in these samples. Therefore, microwave-assisted $\mathrm{BrCl}$ oxidation proved to be more efficient than $\mathrm{BrCl}$ oxidation at room temperature. These results also indicate that for some porewaters oxidation with $\mathrm{BrCl}$ may not be sufficient for the total $\mathrm{Hg}$ determination.

Presented results demonstrate that an open focused microwave system can be successfully applied in different stages of the procedure for the total $\mathrm{Hg}$ and $\mathrm{MeHg}$ determination in sediment and porewater, resulting in an improvement of the method in terms of time and efficiency.

\section{Acknowledgements}

N.M. thanks for a grant from the "Région Nord-Pas-deCalais". Z. Kwokal is thanked for technical assistance. This work was supported by the Ministry of Science and Technology of Croatia and the Seine-Aval Scientific Program.

\section{References}

1. Quevauviller, P.; Imbert, J.-L.; Olle, M. Microchim. Acta 1993, $112,147-154$.

2. Morales-Rubio, A.; Mena, M.-L.; McLeod, C.W. Anal. Chim. Acta 1995, 308, 364-370.

3. Bulska, E.; Kandler, W.; Paslawski, P.; Hulanicki, A. Microchim. Acta 1995, 119, 137-146.

4. Szpunar, J.; Schmitt, V.O.; Donard, O.F.X.; Lobinski, R. Trends. Anal. Chem. 1996, 67, 4250-4270. a)

Mercury in porewater $(\mathrm{ng} / \mathrm{L})$

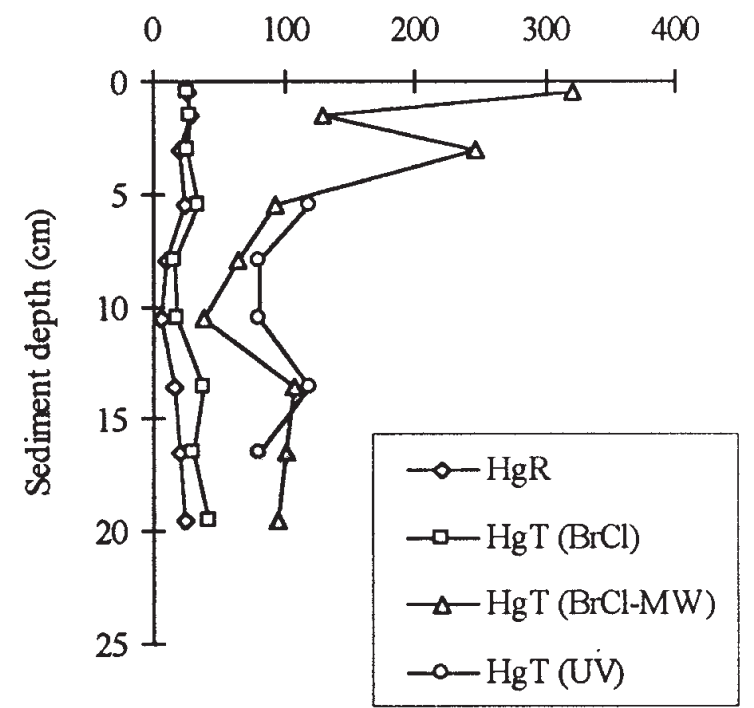

b) Mercury in porewater (ng/L)

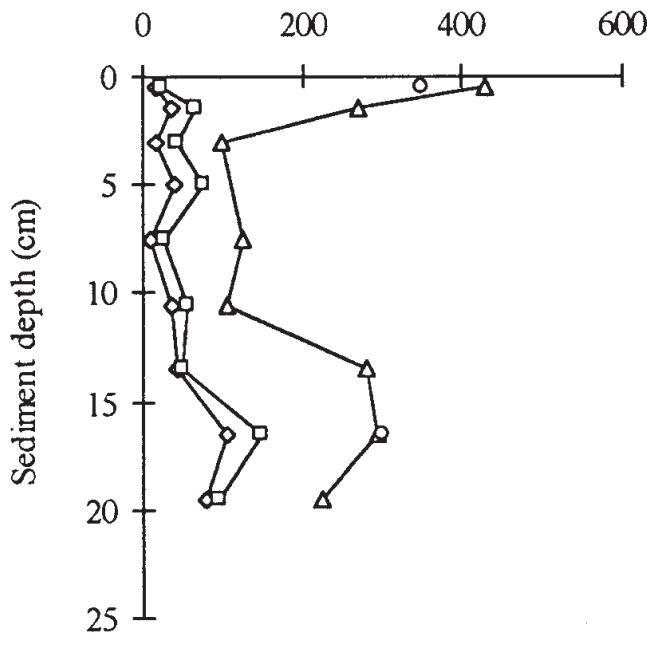

Fig. 2. Porewater mercury profiles in sediment cores of the Seine estuary (a - coastal, b - riverine) sample in Mars 1997 (HgR - reactive mercury, $\mathrm{HgT}$ - total mercury). 
5. Tseng, C.M.; De Diego, A.; Martin, F.-M.; Donard, O.F.X. J. Anal. Atom. Spectr. 1997, 12, 629-635.

6. Cossa, D.; Sanjuan, J.; Cloud, J.; Stockwell P.B.; Corns, W.T. J. Anal. Atom. Spectr. 1995, 10, 287-291.

7. Mikac, N.; Gressier, S.; Wartel, M. Analusis 1999, 27, 472475.

8. Bloom, N.S.; Cercelius, E.A. Mar. Chem. 1983, 14, 49-59.

9. Mikac, N.; Kwokal, Z. Croat. Chem. Acta 1997, 70, 271-288.

10. Horvat, M.; Bloom, N.S.; Liang, L. Anal. Chim. Acta 1993, 281, 135-145.

11. Hintelmann, H.; Falter, R.; Hgen, G.; Evans, R.D. Fresenius J. Anal. Chem. 1997, 358, 358-370.
12. Bloom, N.S.; Colamn, J.A.; Barber, L. Fresenius J. Anal. Chem. 1997, 358, 371-377.

13. Horvat, M.; May, K.; Stoeppler, M.; Byrne, A.R. Applied. Organometall. Chem. 1998, 2, 515-524.

14. Horvat, M.; Quevauviller, P. Anal. Chem. 1999, 71, 155-156A,

15. Falter, R.; Hintelmann, H.; Quevauviller, P. Chemosphere 1999, 39, 1039-1049.

16. Bloxam, M.J.; Hill, J.S.; Worsfolg, J.P. J. Anal. Atom. Spectr. 1996, 11, 511-514.

17. Lamble, K.J.; Hill, S.J. J. Anal. Atom. Spectr. 1996, 11, 10991103. 